\title{
Insulin Pump for Type 2 Diabetes
}

\section{Use and misuse of continuous subcutaneous insulin infusion in type 2 diabetes}

YVES REZNIK, MD ${ }^{1}$

OHAD COHEN, MD ${ }^{2}$

$\mathbf{P}$ rogressive hyperglycemia in type 2 diabetes results from a progressive $\beta$-cell failure together with a state of insulin resistance (1). Insulin deficiency worsens with the natural progression of type 2 diabetes, explaining the escape from oral antihyperglycemic agents and the need for exogenous insulin therapy (2).

The use of external pumps in patients with type 2 diabetes is a recent practice compared with that in type 1 diabetes, and its use is still debated. In only a few countries, such as in France and Israel, continuous subcutaneous insulin infusion (CSII) using an external pump is an alternative in type 2 diabetes that the health authorities have allowed for reimbursement. The rationale for using pump therapy was first suggested by its use in case reports of type 2 diabetes with extreme insulin resistance and poor glycemic control (3-6). In such patients, insulin was administered transiently by intravenous insulin infusion allowing lower mean glucose level despite a $40 \%$ reduction of insulin requirements. The sequential use of 4-week intravenous insulin infusion followed by 1-year CSII in a group of patients with type 2 diabetes patients poorly controlled despite very high insulin requirements allowed a dramatic reduction of $\mathrm{HbA}_{\mathrm{lc}}(-3 \%,-9 \mathrm{mmol} / \mathrm{mol})$, while insulin requirements were reduced by one-third. Such beneficial effects of CSII were attributed to increased insulin sensitivity assessed by the hyperinsulinemiceuglycemic clamp study (7). These observations raised the question as to whether insulin continuous administration by a pump device gives an advantage compared with the conventional approach of insulin intensification by multiple daily injections (MDIs). The evidence base is still under debate and will be discussed in this review.

\section{Is CSII effective for the intensification of insulin therapy in type 2 diabetes?}

Very few randomized controlled studies have looked at the comparative effectiveness of CSII versus MDI (8-11) (Table 1). Two parallel-group studies performed over 6 and 12 months, respectively, included moderately obese type 2 diabetic patients with a mean age range of 55-66 years. Their baseline $\mathrm{HbA}_{1 \mathrm{c}}$ values were moderately high $(8 \%, 64 \mathrm{mmol} / \mathrm{mol}$, and $8.4 \%, 68 \mathrm{mmol} / \mathrm{mol}$ ) despite an insulin therapy with at least one daily injection with or without oral antihyperglycemic agents $(8,9)$. Treatment intensification strategies in these studies compared CSII with a basal/bolus (NPH or a long-acting analog, respectively, plus a rapid-acting analog) and resulted in $\mathrm{HbA}_{\mathrm{lc}}$ lowering of the same magnitude with both MDI and CSII treatments, although the magnitude of $\mathrm{HbA}_{1 \mathrm{c}}$ lowering in both arms was much greater in one study (approximately by -0.5 vs. $-1.6 \%)(8,9)$.

From the ${ }^{1}$ Endocrinology and Diabetes Department, CHU Côte de Nacre, Caen Cedex, France; and the ${ }^{2}$ Division of Internal Medicine, Institute of Endocrinology, Chaim Sheba Medical Center, Tel Hashomer, Israel.

Corresponding author: Yves Reznik, reznik-y@chu-caen.fr.

This publication is based on the presentations from the 4th World Congress on Controversies to Consensus in Diabetes, Obesity and Hypertension (CODHy). The Congress and the publication of this supplement were made possible in part by unrestricted educational grants from Abbott, AstraZeneca, Boehringer Ingelheim, Bristol-Myers Squibb, Eli Lilly, Ethicon Endo-Surgery, Janssen, Medtronic, Novo Nordisk, Sanofi, and Takeda.

DOI: $10.2337 / \mathrm{dcS} 13-2027$

(C) 2013 by the American Diabetes Association. Readers may use this article as long as the work is properly cited, the use is educational and not for profit, and the work is not altered. See http://creativecommons.org/ licenses/by-nc-nd/3.0/ for details.

In contrast to these results, two randomized crossover studies with small numbers of subjects have shown an advantage of CSII in comparison with MDI. In these studies, obese type 2 diabetic patients were successively treated by CSII and MDI for periods of 12 and 18 weeks, respectively $(10,11)$. In these studies, intensification was offered in patients failing to respond to two or more insulin injections per day (NPH or premixed NPH plus rapid-acting analog). Interestingly, these subjects exhibited a baseline $\mathrm{HbA}_{\mathrm{lc}}>9 \%(75 \mathrm{mmol} / \mathrm{mol})$ despite high insulin requirements ( $\geq 1$ units $/ \mathrm{kg} /$ day). For insulin intensification, a rapid-acting analog was used in CSII in both studies, and NPH plus a rapid-acting analog (10) or regular human insulin (11) was used in MDI basal bolus regimens. In these two studies, CSII was more effective than MDI for lowering $\mathrm{HbA}_{1 \mathrm{c}}(-1.2$ vs. $-0.45 \%, P<0.03$, and -0.8 vs. $0.4 \%$, $P<0.01$, respectively). Continuous glucose monitoring was performed in both studies, showing a significant reduction of glucose area under curve with CSII in comparison with MDI $(10,11)$. What may explain such discrepancy observed between the crossover studies compared with the parallel-group studies? Given the heterogeneity of the type 2 diabetic population, it can be difficult to ascertain the potential confounding variables for each study. Nevertheless, there were several differences seen in the selection criteria: $\beta$-cell failure and insulin resistance were likely more severe in the crossover studies as evidenced by the higher baseline $\mathrm{HbA}_{\mathrm{Ic}}$ level, the higher baseline insulin requirement, and the higher number of insulin injections in comparison with the parallel-group studies. The uses of NPH in three of these four studies $(8,10,11)$ and regular insulin in one of the crossover studies (11) instead of the rapid- and longacting analogs are also limiting factors for establishing a comparison between the MDI versus CSII regimens.

The conclusions that can be drawn from the available randomized controlled studies are limited by their paucity and the small size of the sample population studied. A prospective trial involving the 


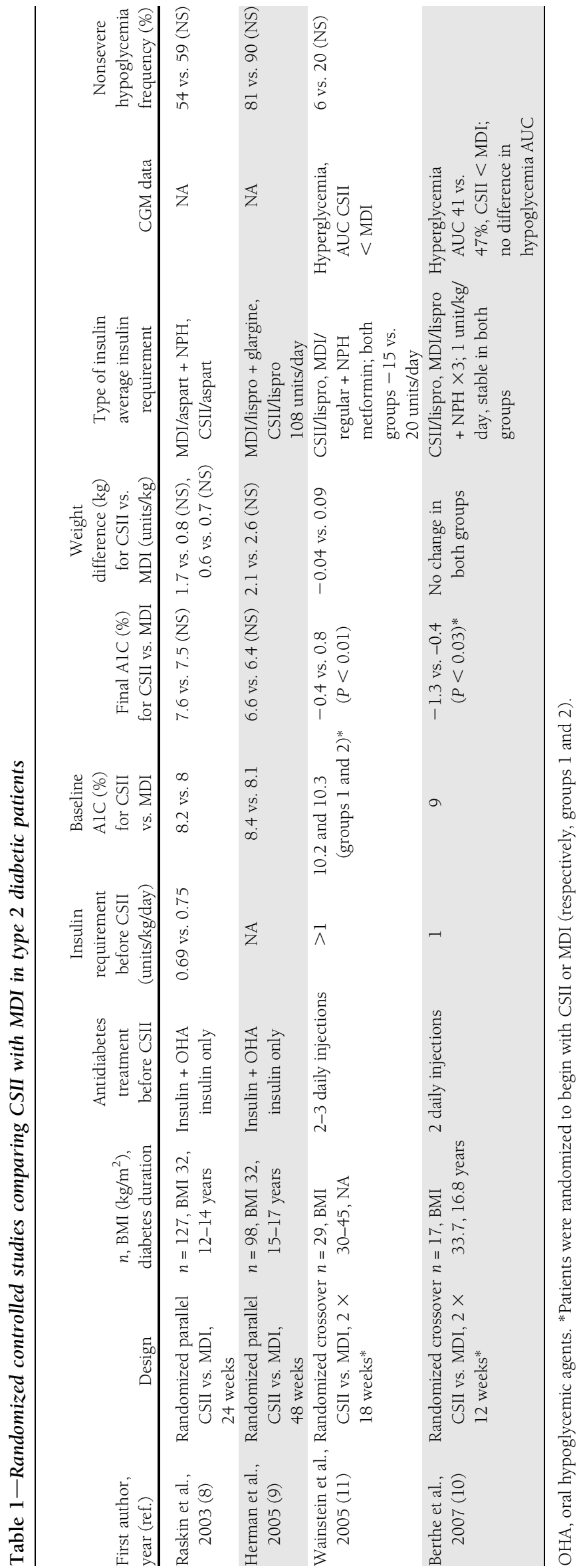

author's centers was designed to compare CSII to MDI in a large cohort of 400 subjects with severe insulin resistance and poor glycemic control. This ongoing study will have sufficient power for providing definitive conclusions on the actual benefit of CSII over MDI for treating hyperglycemia in type 2 diabetes (12).

Although there are limited data on randomized control studies, there are larger longitudinal studies that have shown a durable efficacy of CSII on glucose control (Table 2). A French singlecenter longitudinal retrospective study in 102 poorly controlled type 2 diabetic patients (baseline $\mathrm{HbA}_{\mathrm{lc}} 9.3 \%, 78 \mathrm{mmol} / \mathrm{mol}$ ) demonstrated for the first time a $-1.5 \%$ $\mathrm{HbA}_{1 \mathrm{c}}$ drop $(P<0.001)$ after the switch from an MDI regimen to CSII and no change in the total insulin daily dose. Pump had better efficacy compared with a thrice premix regimen but also with a rapid and a long-acting basal insulin analog regimen. Such efficacy was maintained during 5-year follow-up $(P<$ 0.01 ), suggesting the durability of CSII efficacy for glucose control. Interestingly, the subgroup of patients with a baseline $\mathrm{HbA}_{\mathrm{lc}}<8 \%$ (64 $\left.\mathrm{mmol} / \mathrm{mol}\right)$ did not experience significant improvement of glucose control under CSII (13). Another French single-center study included 51 obese type 2 diabetic patients with poor glucose control $\left(\mathrm{HbA}_{\mathrm{lc}} 9.4 \%, 79 \mathrm{mmol} / \mathrm{mol}\right)$ despite am oral antihyperglycemic agents plus insulin combined regimen. On CSII and after a twofold progressive increase in total insulin daily dose, $\mathrm{HbA}_{1 \mathrm{c}}$ dropped by $-1.7 \%(P<0.001)$, and such benefit was maintained after a 12-year period of follow-up $(P<0.001)$, also suggesting the durability of CSII efficacy in the treatment of type 2 diabetes (14). A third observational study from 31 French hospitals reported results after a 2-year follow up of 100 obese type 2 diabetic patients previously treated by an intensified MDI regimen. CSII was offered when $\mathrm{HbA}_{\mathrm{lc}}$ was $>8 \%(64 \mathrm{mmol} / \mathrm{mol})$, resulting in a $-1.2 \%$ drop at 1 year $(P<0.001)$, which was sustained after a 2-year follow-up $(P<$ 0.001 ) while insulin doses were decreased by $25 \%$ from baseline (15). Two other studies of shorter duration (4-6 months) and smaller cohorts of subjects (58 and 46 patients, respectively) found with CSII an improvement in glucose control in patients previously treated with various treatment regimens (oral antihyperglycemic agent combination, basal insulin analog plus oral antihyperglycemic agents, or MDI) (16) including a combination of 
rapid and basal insulin analogs (17). In these studies, baseline $\mathrm{HbA}_{1 \mathrm{c}}$ of $\sim 8 \%$ (64 $\mathrm{mmol} / \mathrm{mol})$ dropped by $-1.2 \%(P<$ $0.001)$ and by $-0.5 \%(P<0.01)$, respectively $(16,17)$. These studies provide reallife data and, although they lack a control arm, suggest the possibility of pump therapy having durability in sustaining glycemic control. Another issue is the ability of CSII to improve glucose variability with CSII, which was not demonstrated in a randomized controlled study including 107 patients randomized to CSII versus MDI (18).

In type 2 diabetic patients with suboptimal glycemic control despite very high insulin requirements, the use of the concentrated insulin preparation U-500 $(500 \mathrm{IU} / \mathrm{mL})$ may be offered. Its use in a CSII regimen was evaluated in a retrospective study and allowed a significant reduction of $\mathrm{HbA}_{\mathrm{lc}}(-1 \%, P=0.003)$ after 3 months without change in body weight or in total daily insulin dose and with a low rate of severe hypoglycemia (0.1 episodes/patient/year). Such metabolic benefit was maintained for $>66$ months of use (19). The same authors observed similar benefits in a prospective study with the use of U-500 delivered by an Omnipod pump to 21 type 2 diabetic patients who improved both $\mathrm{HbA}_{1 \mathrm{c}}$ $(-1.23 \%, P<0.01)$ and the percentage of time spent in the normoglycemic target range $(+70 \%)(20)$. A recent meta-analysis confirmed such results and reported an increase in patient satisfaction and in cost savings (21).

\section{Is CSII beneficial or detrimental for weight maintenance in type 2 diabetic subjects?}

Most prospective and observational studies evaluating CSII in type 2 diabetic patients were short-term studies, with $\leq 6$ months' duration $(8,10,11,16,17)$ or 1 year's duration $(7,9)$. In the studies with $\leq 6$ months' duration, no weight change $(10,11,17)$ or a $1.7-1.9 \mathrm{~kg}$ weight gain was observed $(8,16)$. In 1 -year duration studies, a weight gain of $\sim 2 \mathrm{~kg}(P<0.01)$ was observed in one (9), while no change occurred in the second (7). In the four randomized studies comparing CSII with MDI, no significant difference in weight change was observed between the two treatments (8-11). Three French retrospective studies gave data of weight variations for $\geq 2$ years: one single center study showed a 4-6 kg weight gain after 6 year follow-up $(P<0.001)$, with a wide range in individual weight change (13).

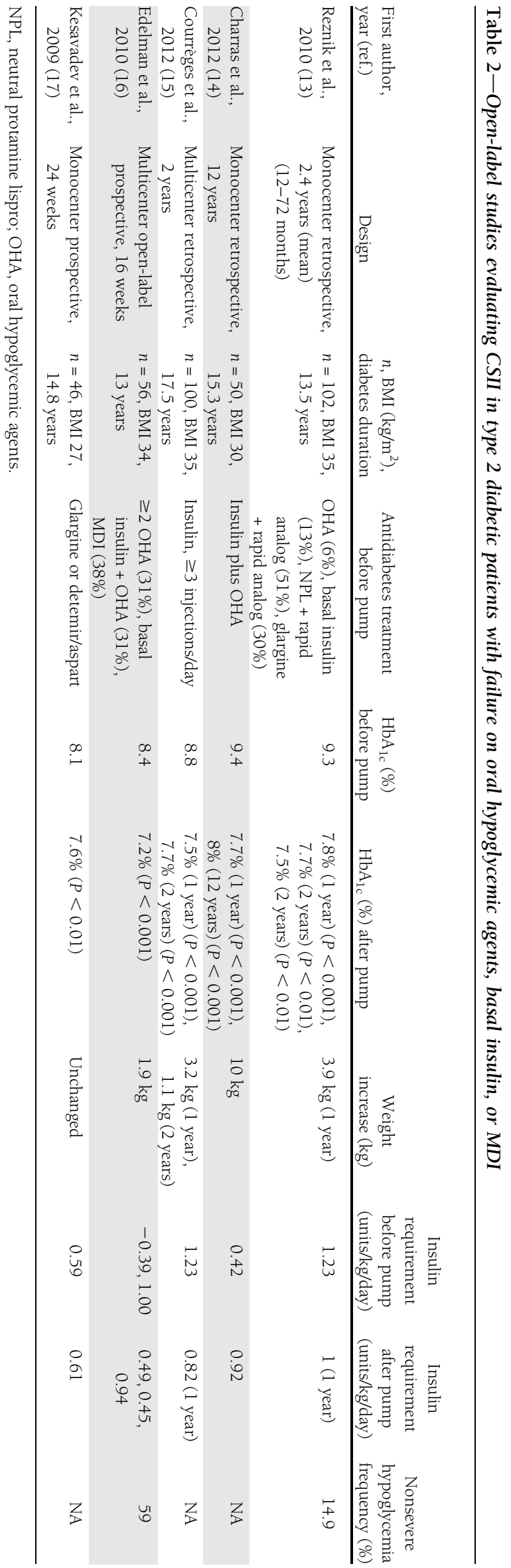


The multicenter French study showed a nonsignificant weight gain $(1.6 \mathrm{~kg}, P=$ 0.69 ) after 2 years possibly related to the $25 \%$ decrease in insulin total daily dose after switching from MDI to CSII (15). In contrast, in one long-term study performed in 51 patients using CSII for at least 7 years, the mean weight gain of 10 $\mathrm{kg}(P<0.001)$ can probably be explained by the twofold increase in the amount of insulin compared with the pre-CSII total daily dose (14). Intensification of insulin therapy by pump is usually accompanied by a moderate weight gain, which seems to correlate with the amount of insulin administered, and pump therapy probably does not provide any additional risk per se in comparison with MDI.

Does the switch from MDI to pump require a modification of the total amount of insulin administered to the type 2 diabetic patient?

Of 10 studies reporting total insulin requirement at the end of treatment, 7 reported no significant change in insulin doses in comparison with the period preceding CSII initiation (8$11,13,16,17$ ), while two reported that insulin dosage was lowered on CSII in comparison with MDI treatment $(7,15)$, and one had a twofold increase of insulin daily dose (14). However, in the latter study baseline insulin doses were much lower (0.42 units/kg/day) than in the other studies. A 1:1 dose switch from MDI to CSII is generally recommended and should not be associated with an increased risk of hypoglycemia in most cases. Because the actual insulin dose injected by the patient may be unknown and insulin dose actually absorbed may be uncertain, a careful blood glucose monitoring and insulin dose titration would be appropriate during the period of pump initiation.

\section{What is the level of satisfaction and quality of life in type 2 diabetic patients on CSII?}

In two randomized parallel-group studies, treatment satisfaction, diabetes impact, and diabetes satisfaction scores improved over time with both CSII and MDI treatments $(8,9)$. The satisfaction score did not differ between MDI and pump in the older population (9), while the CSII group had greater improvement in overall treatment satisfaction compared with MDI in the younger population (8). The 36-Item Short Form Health Survey (SF-36) physical and mental composite score did not change significantly within and between groups in the older population (9). When CSII and MDI were compared in a crossover fashion, the satisfaction subscores were comparable between CSII and MDI (10). A multicenter observational study found after 1 year that health status evaluated in 61 patients on CSII was maintained in $75 \%$ and improved in $20 \%$ of the patients (15). Another 3-year study found an improvement of quality of life stated by the Diabetes Quality of Life (DQOL) and SF-36 questionnaires (22).

\section{Are hypoglycemia and other adverse events limitations in CSII use?}

Hypoglycemia is a major outcome for evaluating the risk-to-benefit ratio of any antihyperglycemic treatment, and most studies have found a very low incidence of severe hypoglycemia in type 1 and type 2 diabetic patients using CSII $(23,24)$. A recent meta-analysis showed an advantage of CSII versus MDI with an odds ratio for severe hypoglycemia of 0.48 (24). Data on the incidence of hypoglycemia in type 2 diabetes are scarce, but the two parallel-group studies, which lasted 6 and 12 months, respectively, showed very low incidence of severe hypoglycemia if any (no event in the study by Raskin et al. [8] and 2.3\% in that by Herman et al. [9]). In the former, a nonsignificant reduction ( 0.8 vs. 1.2 per patient-month) was observed on CSII compared with MDI. Nocturnal hypoglycemia rate was similar for both treatment groups (8). In the latter, the event rates per patientyear were 0.08 vs. 0.23 for CSII vs. MDI, respectively $(P=0.61)$. The incidence of mild hypoglycemia was similar in both groups (1.08 vs. 1.22 per patient-week, $P=0.33$, CSII vs. MDI) (9). The percentage of patients who reported at least one minor hypoglycemic episode during these two studies was also similar for both treatments (Table 1). In the two crossover studies $(10,11)$, the same percentage of patients reported at least one hypoglycemic episode (Table 2), and 24-h CGMS recordings in the former study showed no difference of hypoglycemic duration between both treatment groups (10). Other adverse events reported with the use of CSII included hyperglycemia (8), injection site reaction $(8,9)$, and technical problems $(8)$.

\section{Is pump a useful adjunct for type 2 diabetic women during pregnancy?}

Pregnancy outcomes in women with pregestational type 2 diabetes seem to be either similar (25) or worse (26-28) in comparison with type 1 diabetic patients.
Lack of comprehensive and intensive metabolic control of pregestational type 2 diabetic patients before and during gestation has been hypothesized to underlie such serious adverse fetal outcome (29). Several organizations such as the National Institute for Health and Clinical Excellence and International Diabetes Federation's Global Diabetes in Pregnancy Guideline recommend insulin as optimal therapy ideally initiated prior to pregnancy, which is often not done (29$31)$. As the glycemic target in type 2 diabetic pregnancies is similar to that in type 1 , the majority of women will therefore require complex multiple daily dose regimens. Additionally, insulin requirements vary according to the phase of the pregnancy, adding to the complexity of treatment in patients who usually are unaccustomed to intensive insulin therapy. Intensification in the management of pregnancy in type 2 diabetes women would greatly improve pregnancy outcome, as shown in the Atlantic Diabetes in Pregnancy (Atlantic DIP) intervention (32). In such circumstances, CSII use has the potential to be one of the components in assisting patients with type 2 diabetes with the complexity of insulin therapy regimens during gestation. The potential advantages of CSII use in type 2 during pregnancy includes 1) a better glucose control than with MDI; 2) allowance of temporary basal rates and flexible boluses, which are important throughout pregnancy and are not available with MDI; 3) a decrease in hypoglycemia rate; 4) assistance for weight maintenance; and 5) an improvement in quality of life. Data downloads from insulin pumps, glucometers, and continuous glucose monitoring systems facilitate insight into patients' control, behavior, and educational needs. Average insulin requirements for women with type 2 diabetes using CSII range from 0.6 units $/ \mathrm{kg}$ during the first trimester to 0.8 units $/ \mathrm{kg}$ in second trimester and 1.03 units/kg in the last trimester, but the variability is high (O. Cohen, unpublished observation). Approximately $50 \%$ of the total daily insulin is administered as long-acting insulin analog. Hitherto, no randomized control study on pump use in type 2 diabetes during pregnancy has been published. Retrospective data have shown that in selected "difficult to manage" patients with type 2 diabetes from ethnic backgrounds with high prevalence of obesity and type 2 diabetes, failing to reach target glycemia or with fetal growth 
acceleration on high doses of insulin with at least four injections per day, insulin pump therapy was safe and effective (33). It is our prediction that with the growing concern over pregnancy outcomes in type 2 diabetes (34), more retrospective data and prospective randomized trials will be available using current pumps, modern consumables (catheters, tubing, etc.), and updated data-management systems.

Insulin pump therapy may be offered to pregnant women with gestational diabetes mellitus or type 2 diabetes who fail to obtain adequate glycemic control with a basal/bolus regimen, need very high insulin requirements, or experience persistent accelerated fetal growth despite optimal conventional MDI regimen.

\section{Is the use of oral or other injectable antihyperglycemic agents recommended with CSII?}

The use of oral antihyperglycemic agents may be beneficial in type 2 diabetic patients treated with intensive insulin therapy in order to promote better glycemic control, reduce insulin requirement, and limit weight gain (35). Few studies have tested such a hypothesis in CSIItreated type 2 diabetic patients. An approach was proposed consisting of the maintenance of sulfonylurea together with CSII, with a titration of the oral antihyperglycemic agent aiming to control either fasting glucose or postprandial glucose level. Both strategies were safe and effective for lowering $\mathrm{HbA}_{1 \mathrm{c}}$ (20). Metformin may be a helpful adjunct to CSII for long-term maintenance of $\mathrm{HbA}_{1 \mathrm{c}}$ lowering together with weight gain limitation $(35,36)$. In one study, CSII was provided overnight to type 2 diabetes patients not at goal on oral medications and effectively reduced fasting plasma glucose without occurrence of major hypoglycemia (37). Novel injectable antihyperglycemic agents such as glucagon-like peptide-1 analogs and mimetics have been recently combined with insulin therapy for the treatment of type 2 diabetes with positive results on weight reduction and glycemic control (38). It is foreseeable that combination therapy with CSII in type 2 diabetes will bring similar advantages. No study on type 2 diabetes management has yet demonstrated the efficacy of oral antihyperglycemic agents or glucagon-like peptide-1 analogs in adjunct with CSII in a randomized controlled fashion.
Use of CSII in clinical practice: what are possible indications?

Guidelines from the European Association for the Study of Diabetes and the American Diabetes Association advise a progressive intensification of insulin therapy in type 2 diabetic subjects who fail to respond to therapy with noninsulin antihyperglycemic agents. The basal/bolus regimen combining a rapid-acting and a long-acting insulin analog is recommended as the most precise and flexible regimen for the intensification of insulin therapy (39), while pump therapy is not even mentioned as an alternative. In the author's opinion, pump therapy may be offered in situations of severe chronic hyperglycemia despite high insulin requirements. Such patients are generally obese, exhibit high abdominal fat content, and do not respond to nutritional counseling for restricting carbohydrate or fat intake. One may hypothesize that reduction of postmeal excursions with CSII $(8,10,11)$ may limit the deleterious consequences of hyperglycemic peaks on diabetes complications such as cardiovascular lesions (40). Pump therapy may be offered to patients on at least two injections per day (41) and may be an alternative to the thrice daily premixed NPH/rapid analog combination or the four to five daily injections regimen combining a long-acting insulin analog plus a rapid-acting analog $(10,11,13,16,17)$. Decision to switch from MDI to CSII may also be based on cost-effectiveness considerations $(42,43)$. Other indications of CSII in type 2 diabetes may include extreme insulin resistance syndromes such as lipodystrophy syndromes, pregnancy, and insulin allergy (44). Insulin allergy may occur in type 2 diabetic patients on insulin MDI, and local or generalized allergy manifestations were resolved by a switch to rapid analog insulin administered by CSII $(44,45)$. The mechanism of antigenicity/immunogenicity modulation by CSII remains elusive (45).

Quality of life is also an end point to take into consideration for the indication of pump therapy and may be improved after switching from MDI to pump (22).

The ability to manage with the pump device may also be evaluated in order to select candidates for CSII. With proper training and when necessary a simplified approach, many patients can be candidates who may have otherwise not been considered, including aged patients who are not current users of electronic devices or patients with partial autonomy with their pump device who nevertheless may obtain an improved glucose control (13). The absence of cognitive or operative disability that would compromise pump use may be evaluated by a team experienced in pump therapy. Mild cognitive dysfunction or anxious or depressive mood may be detected with specialized questionnaires validated in this setting in order to reinforce educational strategies in these patients (46). Few contraindications should be ruled out such as proliferative retinopathy, psychiatric disorders, lack of motivation for using pump, or mental or physical disability. In partially autonomous or dependent patients, assistance may be provided by a nurse for managing the pump device, as allowed by health care authorities in some countries as in France (41).

\section{What are the caveats for the use of CSII in type 2 diabetes?}

Patients with insulin-resistant type 2 diabetes use large amounts of insulin per day $(>0.8$ units $/ \mathrm{kg})$. With the pharmacodynamics and pharmacokinetics of current short-acting insulin analogs, the level of circulating and active insulin is high throughout the day. Consequently, the need for fine-tuning of bolus dosage according to carbohydrate loads and for multiple basal rate, which proves efficiency in type 1 diabetic patients on CSII, may not be necessary in most patients with type 2 diabetes (47). In the French cohorts, better glycemic control was achieved using one or two basal rates and using fixed bolus dosages (13-15). Conversely, an unnecessarily complex educational approach for pump use in type 2 diabetic management might deter potential patients from using CSII.

Device handling might be complicated with current pump devices. High insulin daily dosages require frequent reservoir changes. Prefilling cartridges might simplify device handling. Finally, insulin omission is common in type 2 diabetic patients (mainly due to forgetfulness) and is a contributor to lack of glycemic control in MDI and CSII patients as well (48). The possibility of downloading a patient's pump data may play a contributing role to addressing this issue, as it allows the health care professional to follow patient's adherence and to intervene with personalized educational programs.

\section{Is pump use relevant from a medico-economic perspective in a strategy of type 2 diabetes insulin intensification?}

A retrospective study performed in the U.S. by Medtronic Inc. over a 4-year 
period analyzed changes in antihyperglycemic agent use after CSII initiation in 943 type 2 diabetic patients. The mean number of antihyperglycemic drugs decreased by $46 \%$, and more than one-third of type 2 patients previously taking oral antihyperglycemic agents discontinued oral therapy after CSII initiation. Moreover, the rate of emergency department visits and inpatient admissions significantly decreased after CSII initiation (42). A recent insurer cost-of-care study commissioned by Medtronic Inc. and performed among type 2 diabetic patients on 2009-2010 data from the Market-Scan Commercial Research Database from Thomson Reuters analyzed the diabetes treatment costs from 154,000 type 2 diabetic patients on MDI (78\%) or pump therapy (22\%). In the break-even analysis, savings were achieved with pump therapy from lower insulin doses and oral antihyperglycemic agents use, and the initial pump investment was offset by this savings after 2 years and 3 months of an average daily insulin consumption of 169 units (43).

These latter data do not take into account the potential cost-effectiveness of lowering $\mathrm{HbA}_{\mathrm{lc}}$ with an intensified CSII insulin regimen if the demonstration is made in future studies of its superiority compared with MDI intensified regimen. Pump therapy thus appears in some instances relevant for saving costs related to diabetes therapy.

\section{Conclusions}

Pump therapy is a promising approach for insulin therapy intensification in type 2 diabetes. Despite limited data from randomized control studies, longitudinal data in actual use settings suggest that CSII may be preferred to MDI in type 2 diabetic patients with severe insulin resistance and poor glycemic control despite sufficient insulin titration and adherence to recommendations on diet and exercise (13-15). The selection of candidates for pump therapy should integrate the patient's ability to cope with the pump device, the absence of major cognitive or operative disability, acceptable adherence to self-monitoring glucose control, and personal willingness to use an insulin pump. A personalized approach of pump management may allow a substantial number of type 2 diabetic patients to be candidates for pump therapy. Pump treatment in patients with appropriate indications should be associated with limited incidence of adverse events and weight gain, although the individual patient response is not predictable.

Acknowledgments - Y.R. carried out clinical trials as co-investigator for Medtronic, Eli Lilly, and Novo Nordisk; provided advisory services to Medtronic, Abbott, and Eli Lilly; and attended conferences organized by Eli Lilly and Medtronic as a contributor. O.C. carried out clinical trials as co-investigator for Medtronic, Eli Lilly, Novo Nordisk, and Sanofi and provided advisory services and lectures to Medtronic, Eli Lilly, and Sanofi. No other potential conflicts of interest relevant to this article were reported.

Y.R. and O.C. wrote the manuscript and contributed to tables and editing. Y.R. is the guarantor of this work, and, as such, had full access to all the data in the study and takes responsibility for the integrity of the data and the accuracy of the data analysis.

\section{References}

1. Gerich JE. The genetic basis of type 2 diabetes mellitus: impaired insulin secretion versus impaired insulin sensitivity. Endocr Rev 1998;19:491-503

2. U.K. Prospective Diabetes Study Group. U.K. prospective diabetes study 16 . Overview of 6 years' therapy of type II diabetes: a progressive disease. Diabetes 1995;44:1249-1258

3. Garvey WT, Olefsky JM, Griffin J, Hamman RF, Kolterman OG. The effect of insulin treatment on insulin secretion and insulin action in type II diabetes mellitus. Diabetes 1985;34:222-234

4. Gormley MJ, Hadden DR, Woods R, Sheridan B, Andrews WJ. One month's insulin treatment of type II diabetes: the early and medium-term effects following insulin withdrawal. Metabolism 1986;35: 1029-1036

5. Andrews WJ, Vasquez B, Nagulesparan M, et al. Insulin therapy in obese, noninsulin-dependent diabetes induces improvements in insulin action and secretion that are maintained for two weeks after insulin withdrawal. Diabetes 1984; 33:634-642

6. Wainstein J, Metzger M, Wexler ID, Cohen J, Raz I. The use of continuous insulin delivery systems in severely insulinresistant patients. Diabetes Care 2001;24: 1299

7. Pouwels MJ, Tack CJ, Hermus AR, Lutterman JA. Treatment with intravenous insulin followed by continuous subcutaneous insulin infusion improves glycaemic control in severely resistant Type 2 diabetic patients. Diabet Med 2003; 20:76-79

8. Raskin P, Bode BW, Marks JB, et al. Continuous subcutaneous insulin infusion and multiple daily injection therapy are equally effective in type 2 diabetes: a randomized, parallel-group, 24-week study. Diabetes Care 2003;26:2598-2603

9. Herman WH, Ilag LL, Johnson SL, et al. A clinical trial of continuous subcutaneous insulin infusion versus multiple daily injections in older adults with type 2 diabetes. Diabetes Care 2005;28:15681573

10. Berthe E, Lireux B, Coffin C, et al. Effectiveness of intensive insulin therapy by multiple daily injections and continuous subcutaneous infusion: a comparison study in type 2 diabetes with conventional insulin regimen failure. Horm Metab Res 2007;39:224-229

11. Wainstein J, Metzger M, Boaz M, et al. Insulin pump therapy vs. multiple daily injections in obese Type 2 diabetic patients. Diabet Med 2005;22:1037-1046

12. Opt2mise Glucose Control in Type 2 Diabetes Mellitus (DM) with Insulin Pump Therapy [article online]. Available from http:// ClinicalTrials.gov/show/NCT01182493 Accessed 11 August 2010

13. Reznik Y, MoreraJ, Rod A, et al. Efficacy of continuous subcutaneous insulin infusion in type 2 diabetes mellitus: a survey on a cohort of 102 patients with prolonged follow-up. Diabetes Technol Ther 2010; 12:931-936

14. Charras L, Sanz C, Labrousse-Lhermine F, Cazals L, Hanaire H. Traitement par pompe à insuline dans le diabète de type 2 (DT2): 12 ans de suivi d'une cohorte de 50 patients (Abstract). Diabetes Metab 2012;38: Al1 [in French]

15. Courrèges JP, Donnet JP, Gouet D, et al. Résultats métaboliques obtenus à 2 ans sous pompe à insuline ambulatoire chez des diabétiques de type 2 en échec d'insulinothérapie optimisée (Abstract). Diabetes Metab 2012;38:A98 [in French]

16. Edelman SV, Bode BW, Bailey TS, et al. Insulin pump therapy in patients with type 2 diabetes safely improved glycemic control using a simple insulin dosing regimen. Diabetes Technol Ther 2010;12: 627-633

17. Kesavadev J, Balakrishnan S, Ahammed S, Jothydev S. Reduction of glycosylated hemoglobin following 6 months of continuous subcutaneous insulin infusion in an Indian population with type 2 diabetes. Diabetes Technol Ther 2009;11:517-521

18. Johnson SL, McEwen LN, Newton CA, et al. The impact of continuous subcutaneous insulin infusion and multiple daily injections of insulin on glucose variability in older adults with type 2 diabetes. J Diabetes Complications 2011;25: 211-215

19. Lane WS, Weinrib SL, Rappaport JM, Hale $\mathrm{CB}$, Farmer LK, Lane RS. The effect of long-term use of U-500 insulin via continuous subcutaneous insulin infusion on durability of glycemic control and weight 
in obese, insulin-resistant patients with type 2 diabetes. Endocr Pract 2012;27:1-18

20. Lane WS, Weinrib SL, Rappaport JM, Przestrzelski T. A prospective trial of U500 insulin delivered by Omnipod in patients with type 2 diabetes mellitus and severe insulin resistance. Endocr Pract 2010;16: 778-784

21. Reutrakul S, Wroblewski K, Brown RL. Clinical use of U-500 regular insulin: review and meta-analysis. J Diabetes Sci Tech 2012;6:412-420

22. Labrousse-Lhermine F, Cazals L, Ruidavets JB, Hanaire H; GEDEC Study Group. Long-term treatment combining continuous subcutaneous insulin infusion with oral hypoglycaemic agents is effective in type 2 diabetes. Diabetes Metab 2007;33: 253-260

23. Jeitler K, Horvath K, Berghold A, et al. Continuous subcutaneous insulin infusion versus multiple daily insulin injections in patients with diabetes mellitus: systematic review and meta-analysis. Diabetologia 2008;51:941-951

24. Fatourechi MM, Kudva YC, Murad MH, Elamin MB, Tabini CC, Montori VM. Clinical review: Hypoglycemia with intensive insulin therapy: a systematic review and meta-analyses of randomized trials of continuous subcutaneous insulin infusion versus multiple daily injections. J Clin Endocrinol Metab 2009;94:729740

25. Bell R, Bailey K, Cresswell T, Hawthorne G, Critchley J, Lewis-Barned N; Northern Diabetic Pregnancy Survey Steering Group. Trends in prevalence and outcomes of pregnancy in women with preexisting type I and type II diabetes. BJOG 2008;115:445-452

26. Roland JM, Murphy HR, Ball V, Northcote-Wright J, Temple RC. The pregnancies of women with Type 2 diabetes: poor outcomes but opportunities for improvement. Diabet Med 2005;22: 1774-1777

27. Clausen TD, Mathiesen E, Ekbom P, Hellmuth E, Mandrup-Poulsen T, Damm P. Poor pregnancy outcome in women with type 2 diabetes. Diabetes Care 2005;28: 323-328

28. Balsells M, García-Patterson A, Gich I, Corcoy R. Maternal and fetal outcome in women with type 2 versus type 1 diabetes mellitus: a systematic review and metaanalysis. J Clin Endocrinol Metab 2009; 94:4284-4291

29. Meltzer SJ. Prepregnancy care: a shared responsibility. Diabetes Care 2010;33: 2713-2715

30. National Institute for Health and Clinical Excellence. Diabetes in pregnancy; management of diabetes and its complications from pre-conception to the post-natal period, clinical guideline 63 [article online], 2008. Available from www.nice.org. uk/nicemedia/pdf/CG063Guidance.pdf. Accessed 27 October 2012

31. Murphy HR, Roland JM, Skinner TC, et al. Effectiveness of a regional prepregnancy care program in women with type 1 and type 2 diabetes: benefits beyond glycemic control. Diabetes Care 2010;33:25142520

32. Owens LA, Avalos G, Kirwan B, Carmody L, Dunne F. ATLANTIC DIP: closing the loop: a change in clinical practice can improve outcomes for women with pregestational diabetes. Diabetes Care 2012; 35:1669-1671

33. Simmons D, Thompson CF, Conroy C, Scott DJ. Use of insulin pumps in pregnancies complicated by type 2 diabetes and gestational diabetes in a multiethnic community. Diabetes Care 2001;24:20782082

34. Feig DS, Palda VA. Type 2 diabetes in pregnancy: a growing concern. Lancet 2002;359:1690-1692

35. Wulffelé MG, Kooy A, Lehert P, et al. Combination of insulin and metformin in the treatment of type 2 diabetes. Diabetes Care 2002;25:2133-2140

36. Kooy A, de Jager J, Lehert P, et al. Longterm effects of metformin on metabolism and microvascular and macrovascular disease in patients with type 2 diabetes mellitus. Arch Intern Med 2009;169:616625

37. Parkner T, Møller MK, Chen JW, et al. Overnight CSII as supplement to oral antidiabetic drugs in type 2 diabetes. Diabetes Obes Metab 2008;10:556-563

38. Rizos EC, Ntzani EE, Papanas N, et al. Combination Therapies of DPP4 inhibitors and GLPl analog with insulin in type 2 diabetic patients: a systematic review. Curr Vasc Pharmacol. 22 June 2012 [Epub ahead of print]
39. Inzucchi SE, Bergenstal RM, Buse JB, et al. Management of hyperglycaemia in type 2 diabetes: a patient-centered approach. Position statement of the American Diabetes Association (ADA) and the European Association for the Study of Diabetes (EASD). Diabetologia 2012;55: 1577-1596

40. Ceriello A. Postprandial hyperglycemia and diabetes complications: is it time to treat? Diabetes 2005;54:1-7

41. Lassmann-Vague V, Clavel S, Guerci B, et al.; Société francophone du diabète (ex ALFEDIAM). When to treat a diabetic patient using an external insulin pump. Expert consensus. Société francophone du diabète (ex ALFEDIAM) 2009. Diabetes Metab 2010;36:79-85

42. Lynch PM, Riedel AA, Samant N, et al. Resource utilization with insulin pump therapy for type 2 diabetes mellitus. Am J Manag Care 2010;16:892-896

43. David G, Shafiroff J, Saulnier A, Gunnarsson C. Multiple daily injection (MDI) therapy versus durable insulin pump therapy in type 2 diabetics: a break-even analysis (Abstract). Value Health 2012;15(4): A65

44. Moyes V, Driver R, Croom A, Mirakian R, Chowdhury TA. Insulin allergy in a patient with Type 2 diabetes successfully treated with continuous subcutaneous insulin infusion. Diabet Med 2006;23: 204-206

45. Radermecker RP, Scheen AJ. Allergy reactions to insulin: effects of continuous subcutaneous insulin infusion and insulin analogues. Diabetes Metab Res Rev 2007; 23:348-355

46. Zenia A, Morello R, Joubert M, Reznik Y. Autonomie des patients diabétiques de type 2 pour l'utilisation d'une pompe à insuline: influence des facteurs psychocognitifs et socio-culturels (Abstract). Diabetes Metab 2012;38:A108 [in French]

47. Bergenstal RM, Johnson M, Powers MA, et al. Adjust to target in type 2 diabetes: comparison of a simple algorithm with carbohydrate counting for adjustment of mealtime insulin glulisine. Diabetes Care 2008;31:1305-1310

48. Peyrot M, Rubin RR, Kruger DF, Travis LB. Correlates of insulin injection omission. Diabetes Care 2010;33:240-245 